\title{
ИНВЕСТИЦИИ В ОСНОВНОЙ КАПИТАЛ КАК ФАКТОР РЕАЛИЗАЦИИ ИМПОРТОЗАМЕЩЕНИЯ ПРОДОВОЛЬСТВИЯ *
}

\author{
(c) 2018 Соловьева Татьяна Николаевна \\ кандидат экономических наук, профессор \\ Курская государственная сельскохозяйственная академия им. И.И. Иванова \\ 305021, г. Курск, ул. К. Маркса, д. 70 \\ (c) 2018 Зюкин Данил Алексеевич \\ кандидат экономических наук \\ Курский государственный университет \\ 305000, г. Курск, улица Радищева, 33 \\ E-mail: nightingale46@rambler.ru
}

В статье рассматривается изменение объемов инвестирования в основной капитал отрасли сельского хозяйства в целом по стране, по федеральным округам России и регионам ЦФО. Так же проводится ранжирование регионов ЦФО по приросту объемов производства сельскохозяйственной продукции и приросту инвестиций в основной капитал с целью показать взаимосвязь между этими двумя показателями. В исследовании подтверждается, что инвестирование в сельское хозяйство должно происходить устойчиво и продолжать увеличиваться, чтобы была реальная отдача в виде активизации процессов импортозамещения продовольствия.

Ключевые слова: сельское хозяйство, импортозамещение, аграрно-промышленный комплекс, инвестиции, основной капитал.

Доктрина продовольственной безопасности Российской Федерации Российской Федерации ставит перед правительством задачу по обеспечению населения необходимым продовольствием вне зависимости от импортных источников. На текущем этапе развития страны, по мнению Алтухова А.И. [1], принципиально важным является проведение новой государственной политики, что позволит вывести отечественную отрасль сельскохозяйственного производства на новый уровень и повысит конкурентоспособность отечественных сельхозтоваропроизводителей на международном рынке.

В соответствии с доктриной продовольственной безопасности собственное производство продовольствия в стране должно покрывать потребности населения в продукции зернового и свеклосахарного подкомплексов, картофеле и растительных маслах, а самое важное - в продукции животноводства (мясомолочная продукция), а также рыбного хозяйства. В условиях продовольственного эмбарго необходимость существенного ускорения процессов импортозамещения продовольствия значительно возросла. Поэтому важно максимально задействовать имеющийся природно-ресурсный потенциал сельского хозяйства при этом активировать факторы его дальнейшего развития.

К одним из приоритетных факторов относятся инвестиции в основной капитал предприятий, занимающихся сельскохозяйственным производством и переработкой сельскохозяйственного сырья. Объемы вложений в основной капитал сельскохозяйственных организаций привели к изменению его органического строения. Инвестируя в более производительные машины и оборудование, продуценты продовольствия получают возможность увеличивать эффективность экономической деятельности, ускоряя кругооборот задействованного капитала при росте его объема. При этом оборотный капитал растет опережающими темпами, а органическое строение капитала характеризуется понижательной тенденцией [2].

Как известно, для развития любой отрасли требуются инвестиции, а сельскохозяйственное производство относится к тем отраслям, где срок окупаемости вложенных средств в разы превышает сроки окупаемости затрат в продажах или при добыче полезных ископаемых [3]. Именно инвестиции являются неотъемлемым элементом перехода российской экономики на

* Статья подготовлена при финансовой поддержке РФФИ в рамках научного проекта № 18-310-00211 
инновационный тип развития, который предполагает, что во всех отраслях экономики должна увеличиться доля продукции, произведенной с использованием инновационных технологий [4]. Сельское хозяйство является отраслью, где внедрение инновационных технологий сопровождается рядом трудностей, связанных с особенностями сельскохозяйственного производства [5].

При этом технологическая модернизация производства в одних направлениях сельскохозяйственного производства будет способствовать увеличению их экспортного потенциала, а в других к повышению конкурентоспособности отечественной продукции, чтобы обеспечить потребности внутреннего рынка. Но для этого необходимо создать условия для привлечения в отрасль длинных денег в рамках более мягкой монетарной политики государства, потому что текущее положение дел приводит к необходимости компенсировать стоимость кредитов за счет средств прямой государственной поддержки, что характеризует характер такой помощи как компенсационный [6].

Зернопродуктовый и свеклосахарный подкомплексы АПК относятся к первому направлению сельскохозяйственного производства в России, в которых имеются высокий уровень самообеспеченности на внутреннем рынке и экспортный потенциал. В особенности перспективы наращивания экспорта имеются у зернового хозяйства - стабильного донора валютных поступлений в отечественную экономику, на долю которого приходится свыше трети всей валютной выручки от экспорта продовольствия [7]. Однако возможность интенсивного увеличения объемов поставок российского зерна на мировой рынок возникла из-за рекордных урожаев 2016-2017 гг. при недопотреблении зерна на внутреннем рынке. Поэтому в целях комплексного развития сельского хозяйства и обеспечения продовольственной независимости важно стимулировать инвестиции в развитие направлений потребления зерна на внутреннем рынке, в особенности в качестве кормовой базы для животноводства [8].

Не менее важной отраслью сельскохозяйственного производства, отвечающей за продовольственную независимость страны, является свеклосахарное производство. Россия постепенно увеличивает свой экспортный потенциал и по сахаросодержащей продукции $[9,10]$. Возраста- ющий спрос на готовую кондитерскую продукцию среди населения порождает необходимость в продукции переработки свеклосахарного производства, что требует бесперебойной работы перерабатывающих мощностей, зачастую крайне изношенных и не готовых к ускоренным темпам работы. Поэтому для развития и свеклосахарного подкомплекса АПК на современном этапе крайне важны инвестиционные ресурсы.

Как правило, наиболее крупные инвестиции в сельском хозяйстве приходились на животноводческий подкомплекс АПК, поскольку выращивание животных представляет собой затратный, долгий, трудоемкий, сопровождающийся постоянными рисками процесс (строительство и эксплуатация помещений, закупка племенных животных, корма, риски в развитии и болезни животных, падеж и прочее). После распада СССР животноводческая отрасль страны пришла в упадок, поскольку добровольно фермеры готовы были заниматься менее рискованным растениеводством, поэтому больших усилий стоило прийти к нынешним объемам производства животноводческой продукции. В условиях импортозамещения медленно развивающееся животноводство не сможет обеспечить потребности россиян, поэтому необходимо наращивать ускоренными темпами [11].

Поскольку сельскохозяйственная отрасль находится в более сложных условиях (в силу постоянного недостатка финансовых средств и из-за низкой покупательной способности населения), государство предоставляет сельхозтоваропроизводителям льготные кредиты, налоговые льготы, субсидии и иные меры поддержки [12]. Для повышения интенсивности развития сельского хозяйства, что крайне важно в условиях импортозамещения, требуется увеличивать инвестиции в основной капитал. Рассмотрим, как изменялся объем инвестиций в основной капитал отрасли сельского хозяйства России в 2008-2017 гг. (рисунок 1).

Инвестиции в основной капитал отрасли сельского хозяйства России постепенно увеличивались - в период с 2008 г. по 2017 г. инвестиции в сельское хозяйство возросли на $14,8 \%$. При этом своего максимума объем инвестиций достиг в 2016 г., и сравнивая с показателем 2010 года как точки дна после экономического кризиса, прирост оказался практически двукратным за этот период времени. Тем не менее, сельское хозяйство неодинаково развито на территории 


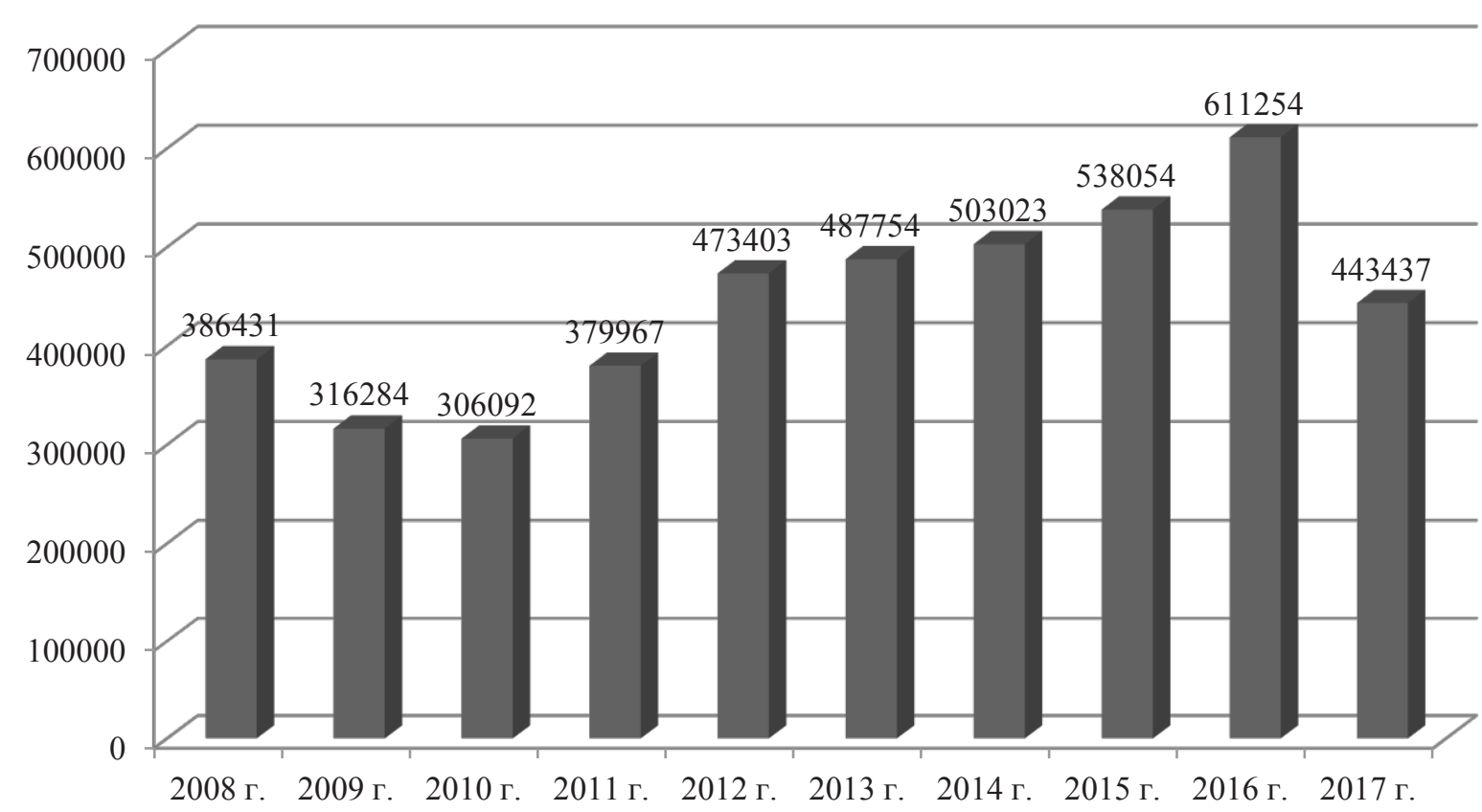

Puc. 1. Инвестиции в основной капитал отрасли сельского хозяйства России, млн. руб. Источник. Составлено автором на основе данных статистического сборника Регионы России [13].

федеральных округов страны, что обуславливается не только природно-климатическими условиями регионов, но и инвестиционными вливаниями в отрасль, что отражает структура инвестиций в основной капитал отрасли сельского хозяйства по федеральным округам (табл. $1)$.

ЦФО является наиболее инвестиционно привлекательным округом для развития сельского хозяйства, в котором сконцентрировано более трети всех инвестиционных потоков в отрасль. Вторым по размеру инвестируемых в сельское хозяйство средств является ПФО, однако его доля в структуре инвестиций постепенно сокращается, что характеризует условия для наращивания инвестиций в этом округе как наименее благоприятные в стране. В свою очередь, наибо- лее активное наращивание инвестиций в основной капитал произошло в ДФО, в особенности в 2017 г. Положительную динамику наращивания показателя выявлена в ЮФО, долю которого выросла с 9,1\% до $11,5 \%$. В то же время в СФО и СЗФО, в 2013 г. доля в структуре инвестиций сокращается. Заметно ухудшил свои позиции и УФО, переместившись на последнее место среди округов, имея сопоставимый показатель с СКФО. Таким образом, прирост инвестиций в основной капитал сельскохозяйственных предприятий происходит в пользу ЦФО, ДФО и южных федеральных округов.

Преимущество в инвестиционной привлекательности ЦФО перед другими регионами страны обусловлено множеством факторов, в том числе и тем, что в ЦФО сконцентрирована

Таблица 1. Доля федеральных округов РФ в структуре инвестиций в основной капитал отрасли сельского хозяйства,\%

\begin{tabular}{|c|c|c|c|c|c|c|}
\hline Регион & 2013 г. & 2014 г. & 2015 г. & 2016 г. & 2017 г. & Изменение,\% \\
\hline ЦФО & 36,5 & 36,5 & 35,8 & 42,7 & 38,6 & 2,1 \\
\hline СЗФО & 8,8 & 8,2 & 7,4 & 6,1 & 7,6 & $-1,2$ \\
\hline ЮФО & 9,1 & 10,4 & 12,4 & 11,8 & 11,5 & 2,4 \\
\hline СКФО & 4,4 & 5,1 & 5,5 & 7,2 & 5,4 & 1,0 \\
\hline ПФО & 21,9 & 21,6 & 21,9 & 17,7 & 16,2 & $-5,7$ \\
\hline УФО & 7,0 & 7,1 & 4,9 & 4,5 & 5,4 & $-1,6$ \\
\hline СФО & 9,7 & 8,7 & 8,7 & 7,0 & 8,1 & $-1,6$ \\
\hline ДФО & 2,6 & 2,5 & 3,5 & 3,1 & 7,2 & 4,6 \\
\hline
\end{tabular}

Источник. Составлено автором на основе данных статистического сборника Регионы России [13]. 
основные мощности по производству сельскохозяйственной продукции. С одной стороны, это является следствием его природного размещения (Центрально-Черноземный район входит в его состав) и неотягощенными климатическими условиями, а с другой стороны, на его территории сосредоточены крупные финансовые и человеческие ресурсы, что выступает преимуществом в развитии любой отрасли.

В ЦФО наиболее благоприятными регионами для ведения сельского хозяйства считаются Воронежская, Курская, Белгородская, Липецкая и Тамбовская области - регионы Центрального Черноземья. Поэтому именно эти регионы относятся к лидерам по величине инвестиций в основной капитал сельского хозяйства. Наиболее инвестиционно привлекательным среди регионов ЦФО является Воронежская область за пять лет здесь инвестировали более 114 млрд. руб., на втором месте оказалась Брянская область, где объем инвестиций превысил 101 млрд. руб. Последующие регионы, входящие в первую пятерку, регионы ЦЧР - Тамбовская, Белгородская и Курская области, где изначально имелся высокий природно-экономический потенциал для развития отрасли.

Наименьшие объемы инвестиций в основ- ной капитал сельского хозяйства фиксируются в Москве, где, собственно, и нет условий для интенсивного развития сельского хозяйства, Костромской и Ивановской областях, которые во всех отношениях отстают от регионов ЦФО по ключевым показателям развития. Что касается прироста инвестиций в исследуемом периоде, то здесь лидирует Калужская область, где прирост составил 610\%. Высокие темпы прироста показала Липецкая область, Смоленская и Тверская области. Так же прирост свыше 100\% фиксируется и в Воронежской области. Отрицательная динамика инвестирования наблюдается в Москве, Брянской области (занимает второе место по объему инвестиций), Костромской, Тамбовской и Ярославской областях (табл. 2).

В силу того, что инвестирование в сельское хозяйство должно приносить плоды в виде прироста объемов производства сельскохозяйственной продукции, целесообразно произвести ранжирование регионов ЦФО по месту, занимаемому регионом по приросту инвестиций в основной капитал и по приросту объема произведенной продукции сельского хозяйства (табл. 3).

Результаты табл. 3 свидетельствуют, что для интенсивного наращивания производства продовольственной продукции важно устойчивое

Таблица 2. Объемы инвестиций в основной капитал отрасли сельского хозяйства в регионах ЦФО, млрд. руб.

\begin{tabular}{|c|c|c|c|c|c|c|c|}
\hline \multirow{2}{*}{ Регион } & \multicolumn{5}{|c|}{ Годы } & \multicolumn{2}{|c|}{ Изменение } \\
\hline & 2013 & 2014 & 2015 & 2016 & 2017 & $(+,-)$ & $\%$ \\
\hline Белгородская область & 12,87 & 11,88 & 13,11 & 15,95 & 15,94 & 3,07 & 23,9 \\
\hline Брянская область & 19,89 & 25,99 & 16,04 & 27,31 & 12,47 & $-7,42$ & $-37,3$ \\
\hline Владимирская область & 1,80 & 1,72 & 2,23 & 1,75 & 2,06 & 0,27 & 14,7 \\
\hline Воронежская область & 15,73 & 15,31 & 17,18 & 32,23 & 34,47 & 18,74 & 119,2 \\
\hline Ивановская область & 0,30 & 0,38 & 0,49 & 0,40 & 0,35 & 0,04 & 14,1 \\
\hline Калужская область & 1,82 & 4,69 & 3,42 & 9,23 & 12,92 & 11,10 & 610,1 \\
\hline Костромская область & 0,56 & 0,42 & 0,49 & 0,41 & 0,38 & $-0,18$ & $-32,5$ \\
\hline Курская область & 14,89 & 6,88 & 8,62 & 18,47 & 16,79 & 1,89 & 12,7 \\
\hline Липецкая область & 5,74 & 7,59 & 9,40 & 14,65 & 15,81 & 10,07 & 175,3 \\
\hline Московская область & 10,33 & 12,12 & 8,39 & 9,77 & 15,03 & 4,70 & 45,5 \\
\hline Орловская область & 3,84 & 3,79 & 4,02 & 5,68 & 7,55 & 3,71 & 96,5 \\
\hline Рязанская область & 3,37 & 4,59 & 4,46 & 4,46 & 5,71 & 2,34 & 69,6 \\
\hline Смоленская область & 1,58 & 0,53 & 1,08 & 1,30 & 3,72 & 2,14 & 135,6 \\
\hline Тамбовская область & 17,33 & 17,23 & 12,89 & 12,48 & 14,12 & $-3,21$ & $-18,5$ \\
\hline Тверская область & 2,42 & 2,15 & 7,24 & 11,01 & 5,53 & 3,11 & 128,6 \\
\hline Тульская область & 2,89 & 1,64 & 4,88 & 5,77 & 5,73 & 2,84 & 98,5 \\
\hline Ярославская область & 2,89 & 2,78 & 2,20 & 2,79 & 2,58 & $-0,31$ & $-10,9$ \\
\hline Москва & 0,36 & 0,75 & 0,83 & 1,79 & 0,21 & $-0,15$ & $-42,6$ \\
\hline
\end{tabular}

Источник. Составлено автором на основе данных статистического сборника Регионы России [13]. 
Таблица 3. Ранжирование регионов ЦФО по размеру прироста производства сельскохозяйственной продукции и приросту объемов инвестиций в основной капитал сельского хозяйства

\begin{tabular}{|c|c|c|c|c|}
\hline \multirow{2}{*}{ Регионы } & \multicolumn{2}{|c|}{$\begin{array}{c}\text { Производство сельскохозяйственной } \\
\text { продукции }\end{array}$} & \multicolumn{2}{|c|}{$\begin{array}{c}\text { Инвестиции в основной капитал } \\
\text { отрасли сельского хозяйства }\end{array}$} \\
\hline & $\begin{array}{c}\text { Прирост } 2017 \text { г. к } \\
2013 \text { г.,\% }\end{array}$ & $\begin{array}{c}\text { Место по размеру } \\
\text { прироста в ЦФО }\end{array}$ & $\begin{array}{c}\text { Прирост } 2017 \text { г. к } \\
2013 \text { г.,\% } \\
\end{array}$ & $\begin{array}{c}\text { Место по размеру } \\
\text { прироста в ЦФО }\end{array}$ \\
\hline Белгородская область & 46,2 & 7 & 23,9 & 10 \\
\hline Брянская область & 94,6 & 1 & $-37,3$ & 17 \\
\hline Владимирская область & 3,9 & 17 & 14,7 & 11 \\
\hline Воронежская область & 34,8 & 10 & 119,2 & 5 \\
\hline Ивановская область & 8,6 & 15 & 14,1 & 12 \\
\hline Калужская область & 45,6 & 8 & 610,1 & 1 \\
\hline Костромская область & $-6,3$ & 18 & $-32,5$ & 16 \\
\hline Курская область & 65,0 & 2 & 12,7 & 13 \\
\hline Липецкая область & 57,2 & 4 & 175,3 & 2 \\
\hline Московская область & 11,9 & 14 & 45,5 & 9 \\
\hline Орловская область & 40,7 & 9 & 96,5 & 7 \\
\hline Рязанская область & 34,7 & 11 & 69,6 & 8 \\
\hline Смоленская область & 13,0 & 13 & 135,6 & 3 \\
\hline Тамбовская область & 54,0 & 5 & $-18,5$ & 15 \\
\hline Тверская область & 53,6 & 6 & 128,6 & 4 \\
\hline Тульская область & 62,5 & 3 & 98,5 & 6 \\
\hline Ярославская область & 28,5 & 12 & $-10,9$ & 14 \\
\hline Москва & 4,9 & 16 & $-42,6$ & 18 \\
\hline
\end{tabular}

Источник. Составлено автором на основе данных статистического сборника Регионы России [10].

поддержание уровня инвестиций в основной капитал. Например, Брянская область занимает 1 место по приросту производства сельскохозяйственной продукции, а по приросту инвестиций - предпоследнее 17 место, что подтверждает влияние на прирост объемов производства именно суммарного объем инвестирования в долгосрочном периоде (в частности, за 5 лет этот показатель среди регионов ЦФО уступает только Воронежской области). Если же анализировать соответствие рангов по приростам, то можно прийти к ошибочному выводу, что прирост объемов инвестирования в основной капитал сельского хозяйства слабо влияет на прирост объемов производства сельскохозяйственной продукции. Хотя даже при таком варианте проведения анализа выявлена определенная взаимосвязь: в Белгородской области (производство - 7 место, инвестиции - 10 место), Ивановской (производство - 15 место, инвестиции - 12 место), Костромской (производство - 18 место, инвестиции - 16 место), Липецкой (производство -4 место, инвестиции -2 место), Орловской (производство - 9 место, инвестиции -7 место), Рязанской (производство - 11 место, инвестиции -8 место), Тверской (производство - 6 место, инвестиции - 4 место), Тульской (производство - 3 место, инвестиции - 6 место), Ярославской (производство - 12 место, инвестиции - 14 место), и Москвы (производство - 16 место, инвестиции - 18 место). Стоит отметить, что более сильная взаимосвязь выражается в отрицательных проявления: мало инвестиций мало произведенной продукции.

Таким образом, в очередной раз становится очевидным то, что в сельском хозяйстве результат инвестирования всегда достижим только в долгосрочной перспективе. Поэтому регионы, где развитие отрасли шло планомерно, а объемы инвестирования не снижались (Воронежская, Белгородская, Курская области), имеются и хорошие результаты развития отрасли. Следовательно, нельзя ожидать хороших результатов в регионах, где вливания в основной капитал носят скачкообразный или единовременный характер, поскольку в сельском хозяйстве для поддержания высоких показателей и их дальнейшего прироста требуется устойчивое инвестиционное обеспечение как элемент устойчивого развития отрасли. 


\section{Библиографический список}

1. Алтухов А.И. Достижение продовольственной независимости страны на основе новой государственной аграрной политики // Региональный вестник. 2016. № 2. С. 2-5.

2. Липченко Е.А. Структурные инвестиции: трансформация воспроизводственного процесса в сельском хозяйстве // Научные труды Вольного экономического общества России. 2017. т. 207. № 5. С. 586-601.

3. Липченко Е.А. Инвестиции и капиталовооруженность в сельском хозяйстве // Экономика сельскохозяйственных и перерабатывающих предприятий. 2018. № 6. С. 40-42.

4. Соловьева T.Н., Пожидаева Н.А. Инновационный подход к использованию природно-экономического потенциала зернового хозяйства // Вопросы социально-экономического развития регионов. 2016. № 1 . С. $10-15$.

5. Соловьева Т.Н., Пожидаева Н.А. О некоторых проблемах развития инноваций в сельском хозяйстве // Вестник Курской государственной сельскохозяйственной академии. 2009. № 2. С. 34-37.

6. Соловьева Т.Н. Государственное регулирование и импортозамещение продовольственной продукции: проблемы и решения / Т.Н. Соловьева, Н.А. Пожидаева, Д.А. Зюкин // Экономика сельскохозяйственных и перерабатывающих предприятий. 2016. № 11. С. 17-20.

7. Алтухов А.И. Стратегия развития зернопродуктового подкомплекса - основа разработки схемы размещения и специализации зернового производства в стране // Вестник Курской государственной сельскохозяйственной академии. 2018. № 5. С. 146-152.

8. Зюкин Д.А. Формирование стратегии развития зернопродуктового подкомплекса АПК как необходимого элемента успешной реализации политики импортозамещения продовольствия // Региональный вестник. 2018. № 6. С. 31-33.

9. Святова О.В., Солошенко Р.В. Рынок сахара России: проблемы и перспективы // Вопросы социально-экономического развития регионов. 2017. № 1 (2). С. 2-7.

10. Святова О.В. Увеличение экспортного потенциала как направление повышения эффективности свеклосахарного подкомплекса АПК России // Вопросы социально-экономического развития регионов. 2016. № 1. С. 2-9.

11. Балакирев Н.А. Животноводство России в условиях импортозамещения // Достижения науки и техники АПК. 2016. № 3. С. 74-76.

12. Старкова О.Я. Инвестиции в основной капитал в сельском хозяйстве // Аэкономика: экономика и сельское хозяйство. 2017. № 3 (15). С. 7.

13. Регионы России. Социально-экономические показатели. [Электронный ресурс]. Режим доступа: http://www. gks.ru/wps/wcm/connect/rosstat_main/rosstat/ru/statistics/publications/catalog/doc_1138623506156 (Дата обращения: 13.01.2019 г.). 